\title{
Genetic profiling of Mycobacterium tuberculosis in Tunisia: predominance and evidence for the establishment of a few genotypes
}

Correspondence

Helmi Mardassi

helmi.merdassi@pasteur.rns.tn

Received 29 June 2007

Accepted 31 January 2008

\author{
Amine Namouchi, ${ }^{1}$ Anis Karboul, ${ }^{1}$ Besma Mhenni, ${ }^{1}$ Neila Khabouchi, ${ }^{1}$ \\ Raja Haltiti, ${ }^{2}$ Ridha Ben Hassine, ${ }^{3}$ Béchir Louzir, ${ }^{4}$ Abdellatif Chabbou ${ }^{5}$ \\ and Helmi Mardassi ${ }^{1}$ \\ ${ }^{1}$ Unit of Typing and Genetics of Mycobacteria, Institut Pasteur de Tunis (Tunisia), 13 Place Pasteur, \\ BP 74, Tunis, Tunisia \\ ${ }^{2}$ Hôpital Régional de Menzel-Bourguiba, Menzel-Bourguiba, Tunisia \\ ${ }^{3}$ Hôpital Régional de Zaghouan, Zaghouan, Tunisia \\ ${ }^{4}$ Hôpital la Rabta, Tunis, Tunisia \\ ${ }^{5}$ Hôpital Abderrahman Mami de Pneumo-Phtisiologie, Ariana, Tunisia
}

Typing analyses of 378 Mycobacterium tuberculosis isolates collected between the years 2001 and 2005 from three northern representative regions of Tunisia revealed a highly homogeneous population. Indeed, $84.9 \%$ of all tuberculosis (TB) cases were attributed to the Haarlem, LAM or T families. Strikingly, within each family, more than $60 \%$ of TB cases were due to a single genotype. ST50 (Haarlem3) and ST42 (LAM9) genotypes were exceptionally predominant, representing $46.3 \%$ of all typed isolates. ST50 showed an increased tendency for clustering and was more predominant in the extreme north of the country. By contrast, the more widespread ST42, which was apparently prevalent 17 years ago, displayed weak cluster individualization and a low transmission rate, consistent with its stable association with the Tunisian population. It is believed that both mass BCG vaccination, strictly applied for four decades, and the high endogamy rate that characterizes the Tunisian population could have profoundly shaped the population structure of $M$. tuberculosis by concurrently favouring the selection and accommodation of particular genotypes.

\section{INTRODUCTION}

Our understanding of the epidemiology of tuberculosis (TB) has vastly increased in recent years owing to the advent of several molecular typing approaches (Barnes \& Cave, 2003). The IS6110-based restriction fragment length polymorphism (IS6110-RFLP) (Van Soolingen et al., 1993), PCR-based spoligotyping (Kamerbeek et al., 1997) and mycobacterial interspersed repetitive units-variable number of tandem repeats (MIRU-VNTR) (Supply et al., 2000) typing methods have been, and are still, the most used. Combined with the recently developed whole genome-based typing approaches, a detailed picture of the global molecular epidemiology of TB has been obtained, revealing a geographically structured population of Mycobacterium tuberculosis with evidence for its adaptation to specific human populations (Brudey et al., 2006; Filliol et al., 2003, 2006; Gagneux et al., 2006; Gutacker

Abbreviations: BCG, Bacille Calmette-Guérin; MDR, multidrug-resistant; MIRU-VNTR, mycobacterial interspersed repetitive units-variable number of tandem repeats; ST, shared type; TB, tuberculosis. et al., 2006; Hirsh et al., 2004; Sola et al., 2001). The factors contributing to the adaptability of $M$. tuberculosis strains or lineages to a particular population are poorly understood and several may be involved. Among these, selective pressure imposed by Bacille Calmette-Guérin (BCG) vaccination could have played an important role (Abebe \& Bjune, 2006; Gagneux et al., 2006).

In Tunisia, a small middle-income country of approximately 10 million inhabitants, the national TB programme, implemented since 1959, has strictly followed the guidelines recommended by the World Health Organization. It is based on systematic double BCG vaccination at birth and at entry to school, passive case detection with sputum microscopy, and prompt short-course multidrug therapy administered under direct supervision of all identified cases. Full implementation of the five major components of the Directly Observed Treatment, Short-course (DOTS) programme was achieved in 1999. A significant decrease in TB incidence (from 58.3 down to 22 per 100000 inhabitants) was reached between 1975 and 2005 
(Tunisian Ministry of Health, 1999, 2005). We reasoned that both long-term mass BCG vaccination and sustained control efforts could have profoundly affected the population structure of $M$. tuberculosis isolates circulating in the country. This particular situation has prompted us to conduct the present study, aimed at providing a detailed insight into the population genetics of circulating $M$. tuberculosis isolates in Tunisia.

\section{METHODS}

Data collection. The study included patients whose clinical specimens were processed in the Laboratory of Mycobacteria of the Institut Pasteur de Tunis between 2001 and 2005. Case data were collected prospectively by trained public health staff using a standardized questionnaire. Information was obtained on gender, age, address, close contacts, previous TB history and associated medical data, such as human immunodeficiency virus (HIV) infection and chest radiography findings.

Bacterial strains and drug susceptibility testing. Mycobacterial strains from 379 different patients were analysed. Primary isolation and culturing of mycobacterial isolates were performed as described elsewhere (Kent \& Kubica, 1985). All isolates were identified as $M$. tuberculosis complex by using biochemical tests, including production of niacin, catalase activity, nitrate reduction, pigment production and growth rate (Kubica, 1973). Drug susceptibility testing against isoniazid, rifampicin, streptomycin, ethambutol and pyrazinamide was performed by the proportional method on Löwenstein-Jensen media at a concentration of $0.2,40,4.0,2.0$ and $200 \mu \mathrm{g} \mathrm{ml}^{-1}$, respectively (Canetti et al., 1969).

Molecular typing of $\boldsymbol{M}$. tuberculosis isolates. The spoligotype patterns were obtained as described by Kamerbeek et al. (1997) using an in-house prepared membrane. The specificity and reproducibility of the hybridization signals obtained with this membrane were assessed by testing a number of $M$. tuberculosis complex strains with known spoligotype profiles (M. tuberculosis H37Rv, Haarlem, Beijing, LAM and CAS, and Mycobacterium bovis, Mycobacterium africanum and Mycobacterium canettii). MIRU-VNTR typing was performed by the method of Supply et al. (2000) and was used to complement spoligotyping for optimal discriminatory power. Briefly, bacteria were first suspended in $500 \mu \mathrm{l}$ ultrapure nuclease-free water, boiled for $10 \mathrm{~min}$, and immediately cooled in an ice bath for $5 \mathrm{~min}$. A $2 \mu \mathrm{l}$ volume of the bacterial lysate was added to the PCR mixture of each MIRU-PCR reaction mix to a final volume of $50 \mu \mathrm{l}$. This mixture contains $0.1 \mu$ HotStarTaq DNA polymerase (0.5 U) (Qiagen) with $10 \mu \mathrm{l}$ Q-solution, $0.5 \mathrm{mM}$ each dATP, dCTP, dGTP and dTTP, $5 \mu \mathrm{l}$ PCR buffer and varying concentrations of $\mathrm{MgCl}_{2}(1.5 \mathrm{mM}, 2 \mathrm{mM}$, $2.5 \mathrm{mM})$ in $1 \times$ PCR buffer. PCR products were run in a DNA thermal-cycler (model 9600; Perkin-Elmer) under the following conditions: $95{ }^{\circ} \mathrm{C}$ for $15 \mathrm{~min}$, followed by 40 cycles of $94{ }^{\circ} \mathrm{C}$ for $1 \mathrm{~min}, 59{ }^{\circ} \mathrm{C}$ for $1 \mathrm{~min}$ and $72{ }^{\circ} \mathrm{C}$ for $1.5 \mathrm{~min}$, with a final extension at $72{ }^{\circ} \mathrm{C}$ for $10 \mathrm{~min}$. PCR products were analysed on a $3 \%$ Metaphor agarose gel (BioWhittaker Molecular Application).

Computer analysis. BioNumerics software (version 4.5; Applied Maths) was used to analyse molecular typing results. The spoligotyping results were entered in a binary format ( 1 and 0 ) according to the hybridization results (positive or negative, respectively) as Excel spreadsheets. Only patterns with $100 \%$ similarity were considered clusters.

MIRU-VNTR types were analysed as character types. Similarities between MIRU-VNTR types were calculated by the categorical coefficient in which all MIRU-VNTR loci were weighted equally. For both spoligotype and MIRU-VNTR results, a dendrogram was constructed by the unpaired group method using arithmetic averages (UPGMA).

Statistical analysis. All included patients were classified into two groups: individuals with clustered or non-clustered M. tuberculosis strains. Categorical data were compared by the chi-square test or Fisher's exact test when expected cell sizes $(N)$ were smaller then five. All tests were performed as two-sided. $P$ values below 0.05 were considered statistically significant. The statistical analyses were done using the GraphPad Prism4 software.

\section{RESULTS}

\section{Study population}

A total of 379 patients were enrolled in this study. Of these, 190 came from the region of Bizerte (north), 155 were from different health-care centres of Tunis (north-east), and 34 originated from the regional hospital of Zaghouan (northeast) (Fig. 1). Samples from Bizerte and Zaghouan were forwarded to us by their respective referral hospitals which process all $\mathrm{TB}$ cases occurring in these regions. TB cases from Tunis represent a coverage rate of $20 \%$. Species differentiation revealed 378 infections with $M$. tuberculosis and 1 infection with M. bovis. The male-to-female ratio was 3 to 1 . The data regarding age and history of patients were available for 200 and 206 patients, respectively. The age of the patients varied from 18 to 87 years old (mean age $=41$

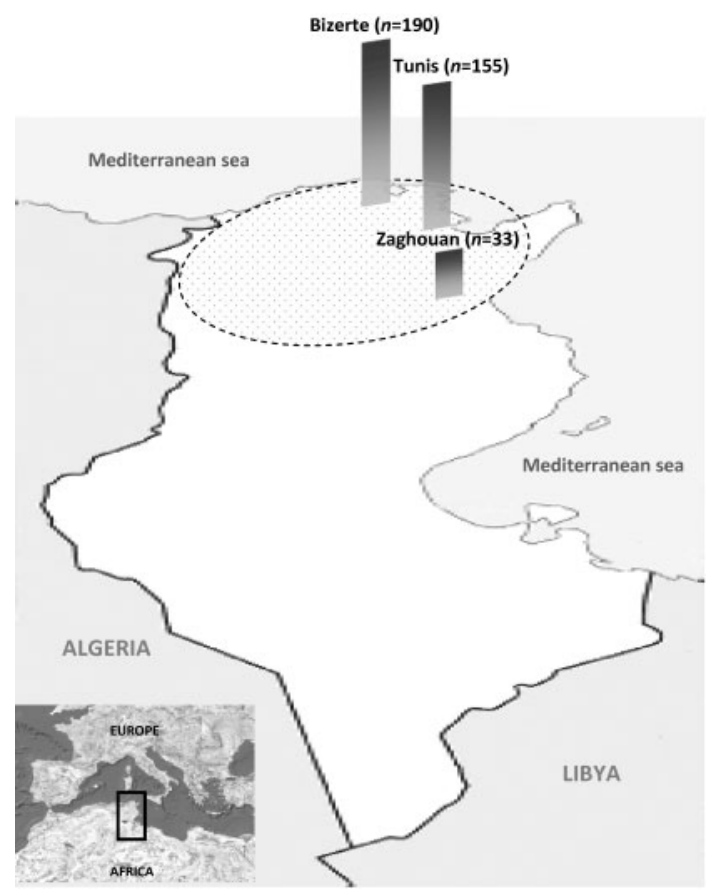

Fig. 1. Map of the north of Tunisia showing the three regions from which the $378 M$. tuberculosis strains were collected. 
years) and $179(86.9 \%)$ of them were considered new cases.

\section{Genetic diversity of $\boldsymbol{M}$. tuberculosis in Tunisia}

Spoligotyping was performed to determine the genetic make-up of M. tuberculosis in Tunisia. Spoligotype patterns were compared with those in the international SpolDB4 database (Brudey et al., 2006) and further analysed with SPOTCLUST (Vitol et al., 2006). Among the $378 \mathrm{M}$. tuberculosis isolates, a total of 75 unique patterns were distinguished (Fig. 2). Among these patterns, 31 were orphan types (43 isolates), as they had no homologue in the SpolDB4 database (Fig. 2). It is worth mentioning that the widespread W/Beijing genotype was absent from this analysed dataset. We could not identify any member of the CAS family, which is thought to represent one of the possible ancestors of the Beijing family (Brudey et al., 2006). Overall, $84.9 \%$ of all Tunisian TB cases were attributed to one of three strain families, namely Haarlem, LAM and T (40.2, 28.3 and $16.4 \%$, respectively).

\section{Predominance of a single genotype within each prevalent strain family}

Phylogenetic analysis revealed the existence of 26 clusters (two or more strains with identical spoligotype patterns) comprising a total of 329 isolates ( $87 \%$ of total isolates), whereas 49 (13\%) clinical isolates were ungrouped (Fig. 2). The largest cluster comprised 110 strains $(29.1 \%)$ and displayed a typical Haarlem3 spoligotype (ST50 according to SpolDB4), followed by the ST42 genotype (65 isolates, $17.2 \%)$, which corresponds to LAM9, and the ST53 genotype (40 isolates; $10.5 \%$ ), which corresponds to T1. Thus $56.8 \%$ of all the typed isolates were associated with ST50, ST42 or ST53; the two first accounting for $46.3 \%$ of all TB cases analysed in this study.

ST50 and ST42, the most predominant spoligotypes, displayed a different geographical distribution (data not shown). The former was more prevalent in the region of Bizerte $(P<0.001)$, the extreme north of the country, while the latter, aside from being prevalent in Bizerte, was most frequently isolated from patients residing in the region of Tunis $(P<0.001)$ and Zaghouan and tended to be more widespread than ST50. Although our sampling originated from three main regions (including the capital of the country), representing approximately one-third of the whole Tunisian population, it would be of interest to explore the relative distribution of these dominant STs on a nationwide scale.

A few isolates (3.7\% of the whole dataset) belonged to the $\mathrm{S}, \mathrm{U}, \mathrm{MANU}$ or $\mathrm{X}$ families, while the majority of the remaining isolates $(11.37 \%)$ were orphans (Fig. 2). These orphan isolates displayed a very low clustering rate and were found to be significantly associated $(P<0.001)$ with young TB patients $(<45$ years).

\section{Transmission analysis}

To gain insight into the transmission rate of $M$. tuberculosis in Tunisia, we subjected the two major STs, ST50 (Haarlem3) and ST42 (LAM9), to MIRU-VNTR analysis. Among the 110 ST50 isolates, 101 were typed, of which 63 fell into 14 clusters (Fig. 3a). Of the 59 ST42 typed isolates, 11 were grouped into 5 clusters (Fig. 3b). The clustering rates for ST50 and ST42 genotypes were estimated to be 62.3 and $18.64 \%$, respectively. The largest cluster of the ST50-Haarlem3 genotype included 26 cases involved in a previously described severe multidrug-resistant (MDR) outbreak (Mardassi et al., 2005), which, at the time of writing, has involved a total of 32 patients. If these 26 outbreak-associated cases were excluded from the analysis, the clustering rate for the ST50 genotype dropped to $49.3 \%$. The increased tendency of ST50 for clustering is statistically significant $(P<0.0001)$ and may reflect a higher transmissibility/adaptability of this particular Haarlem3 genotype, particularly in the region of Bizerte, where it tended to predominate.

Statistical analysis of clustered and non-clustered cases with regard to sex, age, history of $\mathrm{TB}$, location of $\mathrm{TB}$ and antibiotic resistance are detailed in Tables 1 and 2 for both ST50 and ST42, respectively. We found no significant association with clustering for both sex and TB location. In the ST50-Haarlem3 genotype, clustering tended to occur more frequently within patients under the age of 45 years $(P=0.0313)$ and among new cases $(P=0.029)$. With regard to antibiotic resistance, with the exception of the ST50Haarlem3 MDR outbreak, there were no other prominent transmission chains.

\section{Resistance to antitubercular first-line drugs}

Drug susceptibility testing results were available for 371 isolates $(98 \%)$, of which $286(75.5 \%)$ were susceptible to all first-line drugs (Table 3 ). The majority of these isolates were obtained from new TB cases (141/152; $92.7 \%)$. The 85 remaining isolates displayed resistance to one or more first-line anti-TB drugs; 34 of these isolates $(9.1 \%$ of all isolates) were MDR strains. These included the 26 cases that were attributed to the ST50-Haarlem3 MDR outbreak strain. Aside from this outbreak, the overall MDR rate (among previously treated and untreated patients) was at $2.03 \%$ (7/344). Among the resistant isolates other than MDR (51 isolates), monoresistance to streptomycin was the most common $(25 / 41 ; 59.5 \%)$.

\section{DISCUSSION}

We have previously conducted a molecular epidemiological investigation in the extreme north of Tunisia (Bizerte) and described an MDR-TB outbreak due to an ST50-Haarlem3 M. tuberculosis strain endowed with an increased transmissibility potential (Mardassi et al., 2005). In this study, we extended our analysis to two neighbouring regions and 


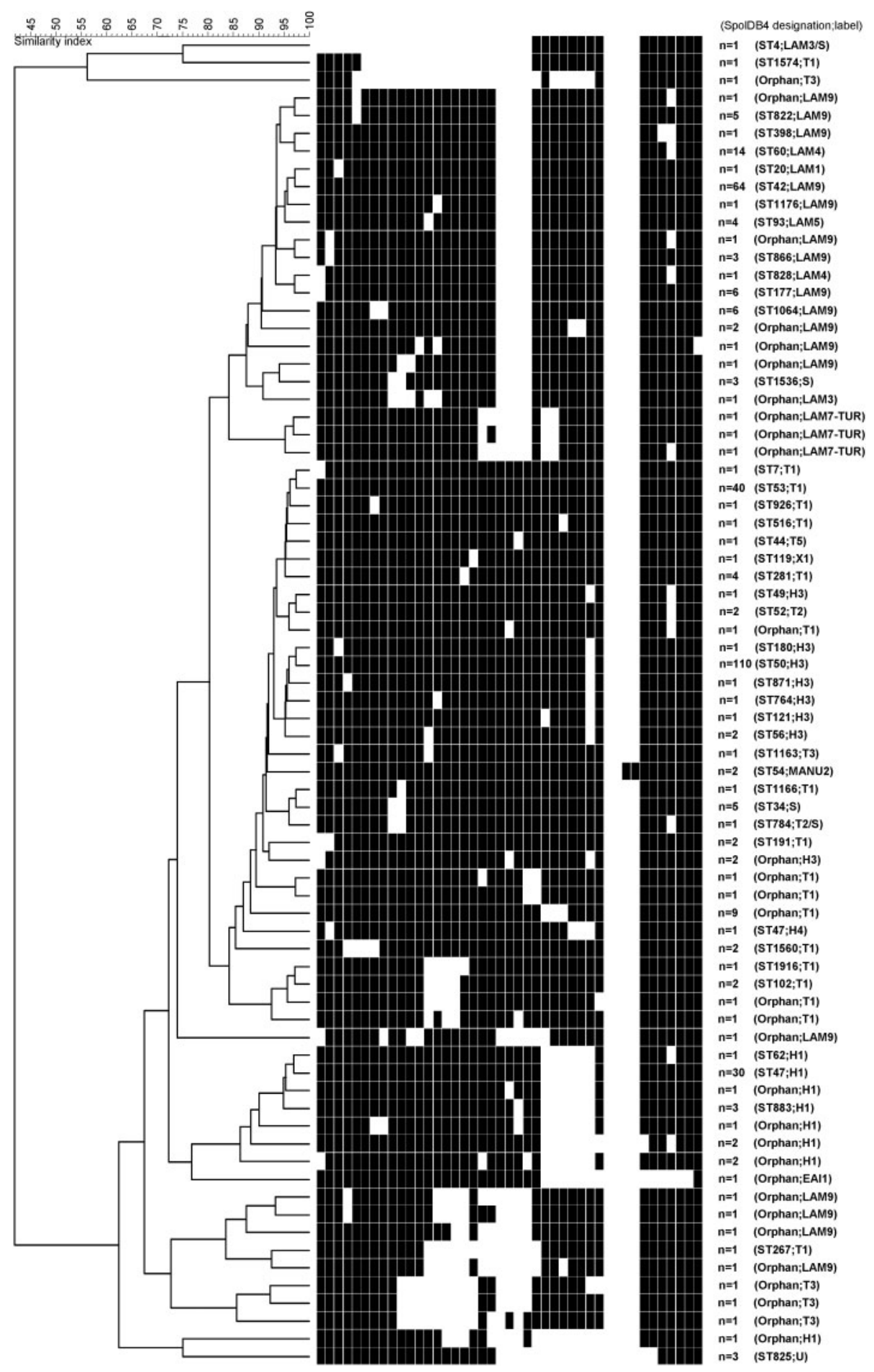

Fig. 2. Dendrogram presentation of the 75 distinct spoligotypes detected among 378 M. tuberculosis isolates collected from three northern Tunisian regions (Bizerte, Tunis and Zaghouan) between 2001 and 2005. Genotypes recognized as orphan in SpolDB4 were labelled further according to SPOTCLUST.

provide a detailed picture of the current TB epidemiology in Tunisia. We highlight the high level of homogeneity of the M. tuberculosis population, as $84.9 \%$ of all TB cases were found to be attributed to the Haarlem, LAM and T families.
The data confirmed the results of a previous study, which on the basis of IS6110-RFLP analysis, revealed that $62 \%$ of M. tuberculosis strains circulating in years 1992-1993 belonged to three genetically related groupings (Hermans 
(a)

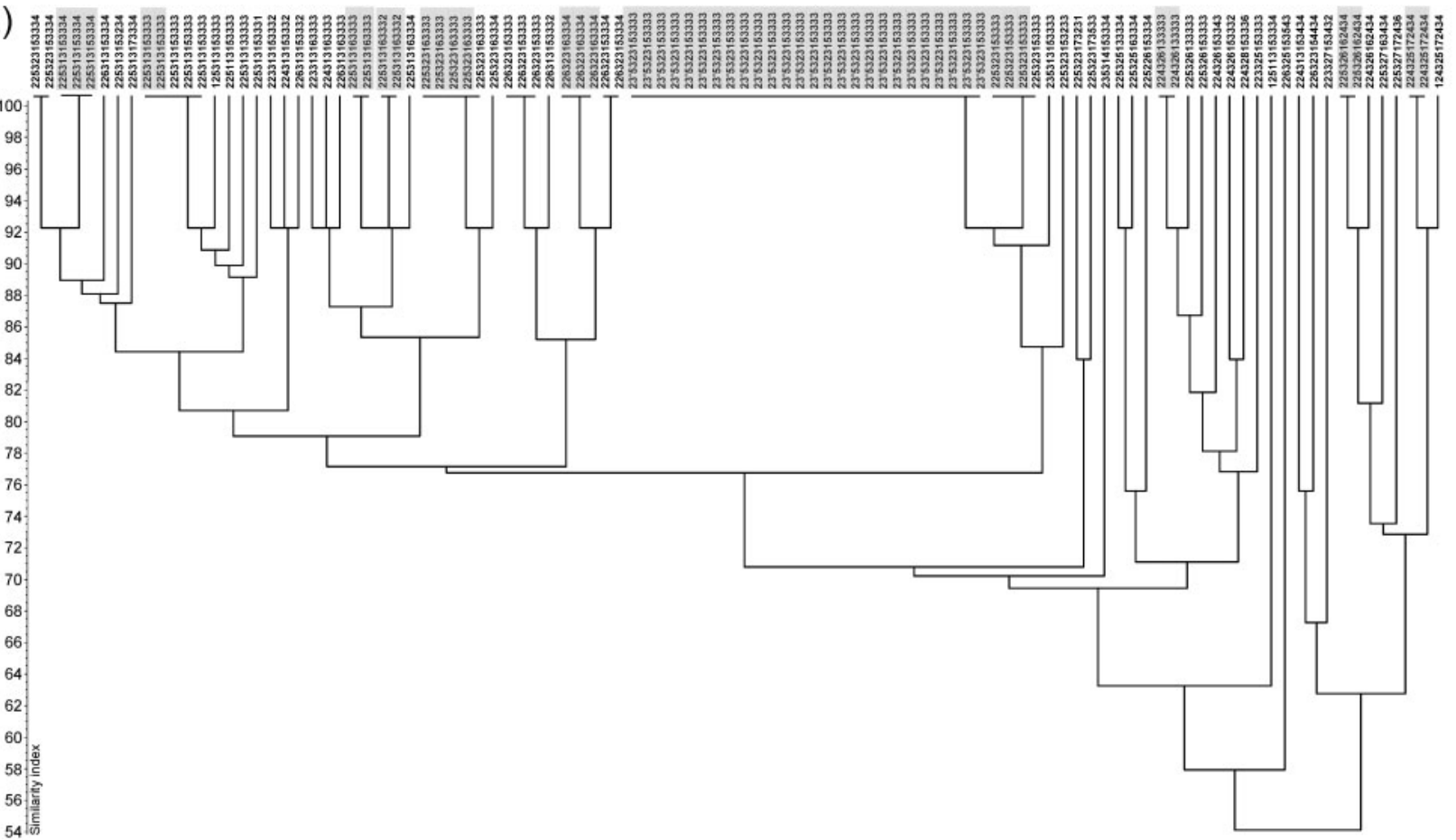

(b)

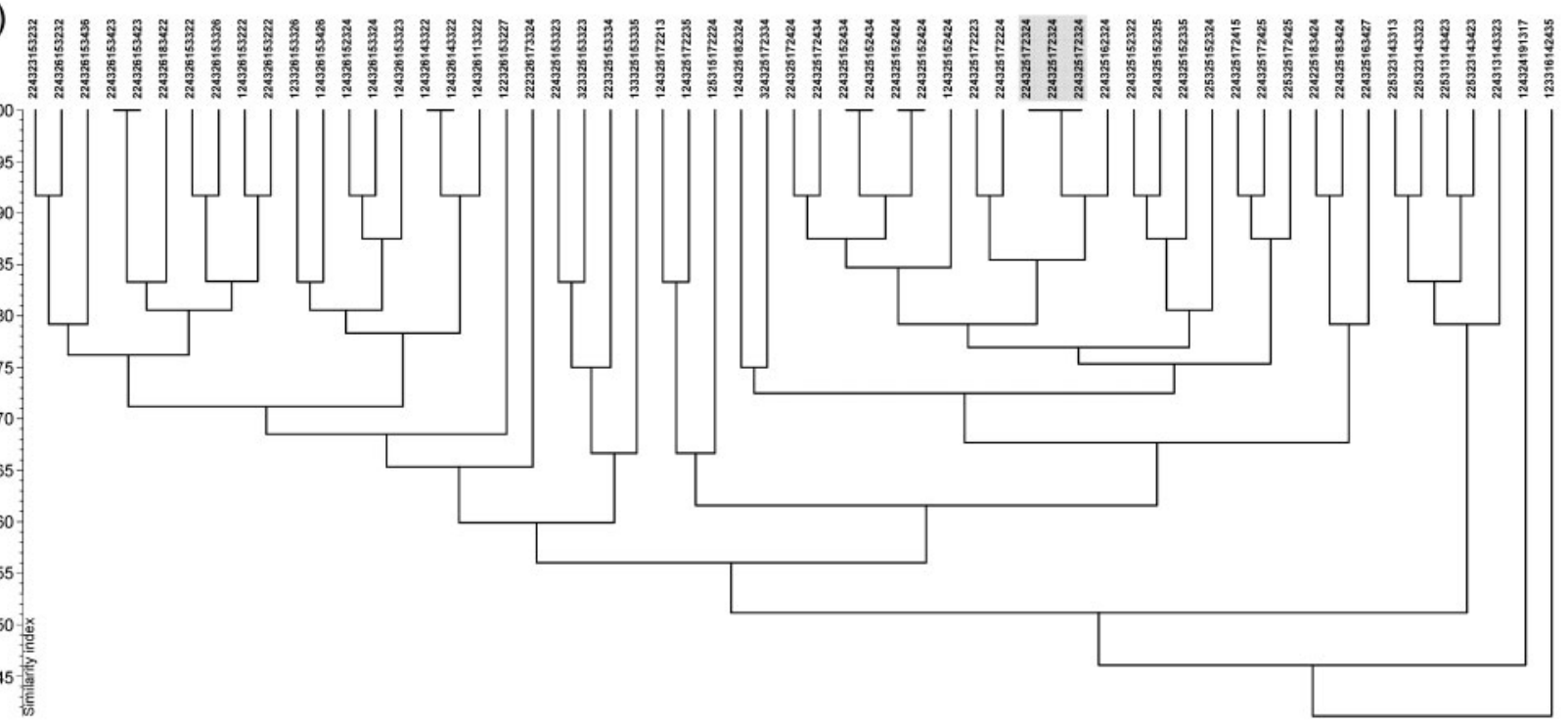

Fig. 3. Genetic relationships of ST50-Haarlem3 (a) and ST42-LAM9 (b) genotypes circulating in Tunisia (2001-2005) as revealed by MIRU-VNTR typing. The dendrograms were constructed by UPGMA. Shading indicates clusters of isolates from the same geographical region, which, according to the epidemiological data, are likely to represent true transmission chains. The largest cluster associated with ST50 represents the previously described Haarlem3 MDR outbreak (Mardassi et al., 2005).

et al., 1995). In fact, we have been able to type $31 \mathrm{M}$. tuberculosis isolates recovered from Tunisian patients in 1990 (available in our laboratory strain collection) and found that $71 \%$ of $\mathrm{TB}$ cases were associated with the Haarlem, LAM and T families (data not shown). Thus one could rightfully assign the three genetically related groupings that predominated in 1992-1993 to the Haarlem, LAM and $\mathrm{T}$ families. According to the most recent version of the worldwide database of spoligotypes (Brudey et al., 2006), the three $M$. tuberculosis families appeared to be also prevalent in the neighbouring countries, namely Algeria and Libya, making up 62 and $65.4 \%$ of the analysed sample, respectively. In fact, the latter three families tended to be prevalent in Africa, but not exclusively, as they have 
Table 1. Analysis of variables associated with ST50-Haarlem3 MIRU-VNTR genotyped Tunisian isolates, 2001-2005

\begin{tabular}{|c|c|c|c|c|}
\hline & \multirow[t]{2}{*}{ Total $(\%)$} & \multicolumn{2}{|c|}{ No. of patients (\%) with characteristic from: } & \multirow[t]{2}{*}{$P$ value $^{\star}$} \\
\hline & & Clustered & Non-clustered & \\
\hline M & $85(84)$ & $56(88.88)$ & $29(76.31)$ & \\
\hline $\mathrm{F}$ & $16(16)$ & $7(11.12)$ & $9(23.69)$ & \\
\hline Age & 66 & $49(74.24)$ & $17(25.76)$ & $0.54(\mathrm{NS})$ \\
\hline$>46$ & $19(28.79)$ & $13(26.54)$ & $6(35.3)$ & \\
\hline History of TB & 68 & $49(72.05)$ & $19(27.95)$ & $0.029(\mathrm{~s})$ \\
\hline New cases & $52(76.47)$ & $34(69.38)$ & $18(94.73)$ & \\
\hline Previously treated & $16(23.53)$ & $15(30.62)$ & $1(5.27)$ & \\
\hline Location of TB & 101 & $63(62.37)$ & $38(37.63)$ & $0.077(\mathrm{NS})$ \\
\hline Pulmonary & $92(91.08)$ & $60(95.23)$ & $32(84.21)$ & \\
\hline PZA & $2(13.34)$ & $1(14.28)$ & $1(12.5)$ & \\
\hline $\begin{array}{l}\text { Resistance to more than one drug } \\
\text { (excluding MDR) } \dagger\end{array}$ & 2 & $1(50)$ & $1(50)$ & 0.535 (NS) \\
\hline $\mathrm{INH}+\mathrm{SM}$ & $1(50)$ & $1(100)$ & 0 & \\
\hline $\mathrm{RIF}+\mathrm{SM}$ & $1(50)$ & 0 & $1(100)$ & \\
\hline $\begin{array}{l}\text { Resistance to more than one drug } \\
\text { (including MDR) } \dagger\end{array}$ & 27 & $26(96.3)$ & $1(3.7)$ & $0.0014(\mathrm{~s})$ \\
\hline $\mathrm{INH}+\mathrm{RIF}+\mathrm{SM}+\mathrm{EMB}+\mathrm{PZA}$ & $17(62.98)$ & $17(65.38)$ & 0 & \\
\hline $\mathrm{INH}+\mathrm{RIF}+\mathrm{SM}+\mathrm{EMB}$ & $6(22.22)$ & $6(23.07)$ & 0 & \\
\hline $\mathrm{INH}+\mathrm{RIF}+\mathrm{SM}+\mathrm{PZA}$ & $1(3.7)$ & $1(3.85)$ & 0 & \\
\hline $\mathrm{INH}+\mathrm{RIF}+\mathrm{EMB}+\mathrm{PZA}$ & $1(3.7)$ & $1(3.85)$ & 0 & \\
\hline
\end{tabular}

${ }^{*}$, Statistically significant; NS, not statistically significant.

$\dagger \mathrm{INH}$, isoniazid; RIF, rifampicin; SM, streptomycin; EMB, ethambutol; PZA, pyrazinamide.

also been reported in Central America, Europe and South America (Brudey et al., 2006). Clearly, the three families have reached very high proportions in Tunisia, a result that is in apparent contradiction with the relative low prevalence of $\mathrm{TB}$ in the country (24 all cases/100000 inhabitants).

The reason for the high predominance of the three strain families in Tunisia stems from the fact that, within each family, a particular ST predominated, each accounting for more than $60 \%$ of TB cases. This picture is reminiscent of a clonal evolution of $M$. tuberculosis in Tunisia and strongly suggests that a selective pressure could have operated to favour the expansion of ST50-Haarlem3, ST42-LAM9 and ST53-T1 genotypes. In the study of Hermans et al. (1995), it was suggested that the majority of the Tunisian isolates descended from three recently expanded clones. Thus TB in Tunisia appears to have evolved towards increased expansion of these clones. The two first STs were particularly predominant $(46.3 \%$ of all $\mathrm{TB}$ cases $)$ and, according to SpolDB4, the prevalence of these two genotypes appears to be particularly high in Tunisia in comparison to the neighbouring Mediterranean countries. Indeed, both STs accounted for 31, 15.6, 9.25 and $12.6 \%$ of all isolates in Morocco, Algeria, Libya and Italy, respectively. Hence, with approximately $50 \%$ of all $\mathrm{TB}$ cases being assigned to two particular genotypes, the population structure of M. tuberculosis in Tunisia tends to be highly restricted in its genetic diversity. In fact, apart from the three families Haarlem, LAM and T, much of the diversity was found to be associated with isolates displaying orphan spoligotypes. The origin of these spoligotypes is at present unclear. However, using SPOTCLUST analysis, all of these orphan spoligotypes could be assigned, with a probability of $0.75-0.99$, to the Haarlem (19.36\%), LAM (45.17\%), T $(32.25 \%)$ and EAI $(3.22 \%)$ strain families. They could have thus resulted from microevolution of endemic genotypes. Of particular interest, three spoligotypes could be related to the LAM7-TUR genotype (Fig. 2). It remains to be seen whether they have been recently introduced or, 
Table 2. Analysis of variables associated with ST42-LAM9 MIRU-VNTR Tunisian genotyped isolates, 2001-2005

\begin{tabular}{|c|c|c|c|c|}
\hline & \multirow[t]{2}{*}{ Total $(\%)$} & \multicolumn{2}{|c|}{ No. of patients (\%) with characteristic from: } & \multirow[t]{2}{*}{$P$ value $^{\star}$} \\
\hline & & Clustered & Non-clustered & \\
\hline Sex & 59 & 11 & 48 & 0.406 (NS) \\
\hline M & $38(64.4)$ & $6(54.54)$ & $32(66.66)$ & \\
\hline $\mathrm{F}$ & $21(35.6)$ & $5(45.46)$ & $16(33.34)$ & \\
\hline Age & 29 & 5 & 24 & 1.000 (NS) \\
\hline$<=45$ & $20(68.96)$ & $4(80)$ & $16(66.66)$ & \\
\hline$>45$ & $9(31.04)$ & $1(20)$ & $8(33.34)$ & \\
\hline History of TB & 44 & 6 & 38 & $0.456(\mathrm{NS})$ \\
\hline New cases & $40(90.9)$ & $5(83.33)$ & $35(92.1)$ & \\
\hline Previously treated & $4(9.1)$ & $1(16.66)$ & $3(7.9)$ & \\
\hline Location of TB & 58 & 11 & 47 & $0.583(\mathrm{NS})$ \\
\hline Pulmonary & $52(89.65)$ & $11(100)$ & $41(87.23)$ & \\
\hline Extrapulmonary & $6(10.35)$ & 0 & $6(12.77)$ & \\
\hline Resistance to one drug only $\dagger$ & 8 & 1 & 7 & $1.0000(\mathrm{NS})$ \\
\hline INH & $1(12.5)$ & 0 & $1(14.28)$ & \\
\hline SM & $6(75)$ & $1(100)$ & $5(71.42)$ & \\
\hline PZA & $1(12.5)$ & 0 & $1(14.28)$ & \\
\hline $\begin{array}{l}\text { Resistance to more than one drug } \\
\text { (excluding MDR }) \dagger\end{array}$ & 1 & $\mathbf{0}$ & 1 & $1.0000(\mathrm{NS})$ \\
\hline $\mathrm{INH}+\mathrm{SM}$ & $1(100)$ & 0 & $1(100)$ & \\
\hline $\begin{array}{l}\text { Resistance to more than one drug } \\
\text { (including MDR) } \dagger\end{array}$ & 1 & $\mathbf{0}$ & 1 & $1.0000(\mathrm{NS})$ \\
\hline $\mathrm{INH}+\mathrm{RIF}+\mathrm{SM}+\mathrm{EMB}$ & $1(100)$ & 0 & $1(100)$ & \\
\hline Pansusceptible strains & 49 & $10(20.4)$ & $39(97.6)$ & 0.669 (NS) \\
\hline
\end{tabular}

${ }^{\star}$ NS, Not statistically significant.

$\dagger \mathrm{INH}$, isoniazid; RIF, rifampicin; SM, streptomycin; EMB, ethambutol; PZA, pyrazinamide.

rather, represent a possible remnant of a historically prevalent clade that could have been linked to the establishment of the Ottoman Empire in Tunisia.

MIRU-VNTR analysis revealed a relatively high clustering rate for the ST50 genotype. Clustering associated with this genotype occurred significantly within patients under the age of 45 years and among new cases, particularly in the indigenous northern Tunisian population. Thus it is very likely that the high level of transmission of this genotype may have contributed to its predominance. Although most of the clustered cases were epidemiologically supported, one should not dismiss the possibility that some patients may not be part of a recent transmission chain, since, as previously shown, the Spol-MIRU12 combination used in this study could lead to misclassification (Scott et al., 2005). By contrast, the ST42 genotype displayed low clustering, was more widespread than ST50, and was found to be predominant in the sample from 1990, accounting for $35.4 \%$ (11 out of 31 ) of TB cases. Although the number of analysed samples from 1990 is limited, it provides a strong indication that ST42 was already established 17 years ago. This, together with the fact that the present study involved samples collected over a relatively long period (5 years), indicates that the predominance of the ST42 genotype is likely to be compatible with a long-term established association with the indigenous population. The predominance of particular genotypes or lineages in a given population has been previously described in Cameroon (Niobe-Eyangoh et al., 2003), Turkey (Zozio et al., 2005) and India (Gutierrez et al., 2006). While in the majority of cases they have been associated with increased recent transmission rates, it remains to be seen whether they have established or evolved towards a stable association with their respective human population.

The homogeneity of the $M$. tuberculosis population in Tunisia has been previously associated with a selective pressure resulting from mass BCG vaccination, which has been, and is still, practised for four decades (Hermans et al., 1995). This could be a plausible explanation, and the fact that in this study we showed that, within the most prevalent strain families, particular genotypes predominated lends further support to this assumption. This finding warrants further evaluation, using animal models, of the ability of the predominant ST50 and ST42 genotypes to circumvent BCG vaccination as previously shown for Beijing strains (Lopez et al., 2003; Abebe \& Bjune, 2006). Moreover, consanguinity and endogamy, which can reach $50 \%$ in certain Tunisian areas (Ben Arab et al., 2004; Riou et al., 1989), may have contributed to the accommodation of particular M. tuberculosis genotypes. Overall, the findings are 
Table 3. Drug resistance in 371 M. tuberculosis isolates from three regions (Bizerte, Tunis and Zaghouan) of nothern Tunisia, 20012005

\begin{tabular}{|c|c|c|c|}
\hline Drug resistance pattern ${ }^{\star}$ & Total & History of TB $\dagger$ & Associated genotypes \\
\hline Resistance to one drug only & $42(11 \%)$ & & \\
\hline INH & 7 & 1 previously treated +4 new cases & $4 \mathrm{H} 3+2 \mathrm{LAM} 9+1 \mathrm{~T} 1$ \\
\hline SM & 25 & 1 previously treated +11 new cases & $\begin{array}{l}3 \mathrm{H} 1+11 \mathrm{H} 3+6 \mathrm{LAM} 9+ \\
1 \mathrm{LAM} 4+2 \mathrm{~T} 1+1 \mathrm{U}+1 \text { unknown }\end{array}$ \\
\hline PZA & 5 & 3 new cases & $2 \mathrm{H} 3+\mathrm{LAM} 9+1 \mathrm{~T} 1+1$ unknown \\
\hline $\mathrm{INH}+\mathrm{SM}+\mathrm{EMB}+\mathrm{PZA}$ & 1 & Not available & $\mathrm{T} 1$ \\
\hline $\mathrm{INH}+\mathrm{SM}+\mathrm{EMB}$ & 1 & New case & $\mathrm{T} 1$ \\
\hline $\mathrm{INH}+\mathrm{SM}$ & 3 & 1 previously treated +1 new case & $1 \mathrm{H} 3+1 \mathrm{LAM} 9+1 \mathrm{~T} 1$ \\
\hline $\mathrm{SM}+\mathrm{RIF}$ & 1 & New case & H3 \\
\hline $\mathrm{SM}+\mathrm{PZA}$ & 1 & New case & LAM9 \\
\hline $\mathrm{INH}+\mathrm{RIF}+\mathrm{SM}+\mathrm{EMB}+\mathrm{PZA}$ & 17 & 9 previously treated +4 new cases & $17 \mathrm{H} 3$ \\
\hline $\mathrm{INH}+\mathrm{RIF}+\mathrm{SM}+\mathrm{EMB}$ & 8 & 2 previously treated +3 new cases & $6 \mathrm{H} 3+1 \mathrm{LAM} 9+1 \mathrm{~T} 1$ \\
\hline $\mathrm{INH}+\mathrm{RIF}+\mathrm{SM}+\mathrm{PZA}$ & 1 & Not available & H3 \\
\hline $\mathrm{INH}+\mathrm{RIF}+\mathrm{EMB}+\mathrm{PZA}$ & 1 & Not available & $\mathrm{H} 3$ \\
\hline $\mathrm{INH}+\mathrm{RIF}+\mathrm{SM}$ & 4 & 2 previously treated & $1 \mathrm{H} 1+2 \mathrm{H} 3+1 \mathrm{LAM} 9$ \\
\hline $\mathrm{INH}+\mathrm{RIF}+\mathrm{PZA}$ & 1 & Not available & $\mathrm{H} 1$ \\
\hline INF + RIF & 2 & Not available & $1 \mathrm{H} 3+1 \mathrm{~S}$ \\
\hline Pansusceptible strains & $286(75.5 \%)$ & 11 previously treated +141 new cases & \\
\hline Not determined & $8(2.5 \%)$ & 4 new cases & \\
\hline
\end{tabular}

${ }^{\star} \mathrm{INH}$, isoniazid; RIF, rifampicin; SM, streptomycin; EMB, ethambutol; PZA, pyrazinamide.

$\dagger$ The history of the patients, whenever available, is indicated.

in line with recent studies which revealed that certain mycobacterial lineages have adapted to specific human populations (Gagneux et al., 2006; Hirsh et al., 2004).

With regard to drug resistance, we have not been able to identify any clustering with the exception of the ST50 MDR outbreak (Mardassi et al., 2005). This certainly reflects the success of the five components of the DOTS strategy, the application of which has reached $100 \%$ coverage rate. This is also another indication that the predominance of ST50 and ST42 could not have simply resulted from increased shedding of bacilli from patients left untreated for prolonged periods.

In conclusion, aside from providing a snapshot of $\mathrm{TB}$ dynamics and drug resistance in Tunisia, our study adds to the compelling evidence suggesting that $M$. tuberculosis tends to adapt to its host population.

\section{ACKNOWLEDGEMENTS}

This investigation received financial support from the UNDP/World Bank/WHO Special Programme for Research and Training in Tropical Diseases (TDR), and from the Tunisian Ministry of Higher Education, Scientific Research, and Technology. We thank Nalin
Rastogi and Thierry Zozio (Institut Pasteur de Guadeloupe) for providing updated statistics on ST50 and ST40 genotypes in the Mediterranean countries.

\section{REFERENCES}

Abebe, F. \& Bjune, G. (2006). The emergence of Beijing family genotypes of Mycobacterium tuberculosis and low-level protection by bacille Calmette-Guérin (BCG) vaccines: is there a link? Clin Exp Immunol 145, 389-397.

Barnes, P. F. \& Cave, M. D. (2003). Molecular epidemiology of tuberculosis. N Engl J Med 349, 1149-1156.

Ben Arab, S., Masmoudi, S., Beltaief, N., Hachicha, S. \& Ayadi, H. (2004). Consanguinity and endogamy in Northern Tunisia and its impact on non-syndromic deafness. Genet Epidemiol 27, 74-79.

Brudey, K., Driscoll, J. R., Rigouts, L., Prodinger, W. M., Gori, A., Al-Hajoj, S. A., Allix, C., Aristimuno, L., Arora, J. \& other authors (2006). Mycobacterium tuberculosis complex genetic diversity: mining the fourth international spoligotyping database (SpolDB4) for classification, population genetics and epidemiology. BMC Microbiol 6, 23.

Canetti, G., Fox, W., Khomenko, A., Mahler, H. T., Menon, N. K., Mitchison, D. A., Rist, N. \& Smelev, N. A. (1969). Advances in techniques of testing mycobacterial drug sensitivity, and the use of sensitivity tests in tuberculosis control programmes. Bull World Health Organ 41, 21-43. 
Filliol, I., Driscoll, J. R., van Soolingen, D., Kreiswirth, B. N., Kremer, K., Valetudie, G., Dang, D. A., Barlow, R., Banerjee, D. \& other authors (2003). Snapshot of moving and expanding clones of Mycobacterium tuberculosis and their global distribution assessed by spoligotyping in an international study. J Clin Microbiol 41, 1963-1970.

Filliol, I., Motiwala, A. S., Cavatore, M., Qi, W., Hazbon, M. H., Bobadilla del Valle, M., Fyfe, J., Garcia-Garcia, L., Rastogi, N. \& other authors (2006). Global phylogeny of Mycobacterium tuberculosis based on single nucleotide polymorphism (SNP) analysis: insights into tuberculosis evolution, phylogenetic accuracy of other DNA fingerprinting systems, and recommendations for a minimal standard SNP set. J Bacteriol 188, 759-772.

Gagneux, S., DeRiemer, K., Van, T., Kato-Maeda, M., de Jong, B. C., Narayanan, S., Nicol, M., Niemann, S., Kremer, K. \& other authors (2006). Variable host-pathogen compatibility in Mycobacterium tuberculosis. Proc Natl Acad Sci U S A 103, 2869-2873.

Gutacker, M. M., Mathema, B., Soini, H., Shashkina, E., Kreiswirth, B. N., Graviss, E. A. \& Musser, J. M. (2006). Single-nucleotide polymorphism-based population genetic analysis of Mycobacterium tuberculosis strains from 4 geographic sites. J Infect Dis 193, 121-128.

Gutierrez, M. C., Ahmed, N., Willery, E., Narayanan, S., Hasnain, S. E., Chauhan, D. S., Katoch, V. M., Vincent, V., Locht, C. \& other authors (2006). Predominance of ancestral lineages of Mycobacterium tuberculosis in India. Emerg Infect Dis 12, 1367-1374.

Hermans, P. W., Messadi, F., Guebrexabher, H., van Soolingen, D., de Haas, P. E., Heersma, H., de Neeling, H., Ayoub, A., Portaels, F. \& other authors (1995). Analysis of the population structure of Mycobacterium tuberculosis in Ethiopia, Tunisia, and The Netherlands: usefulness of DNA typing for global tuberculosis epidemiology. J Infect Dis 171, 1504-1513.

Hirsh, A. E., Tsolaki, A. G., DeRiemer, K., Feldman, M. W. \& Small, P. M. (2004). Stable association between strains of Mycobacterium tuberculosis and their human host populations. Proc Natl Acad Sci U S A 101, 4871-4876.

Kamerbeek, J., Schouls, L., Kolk, A., van Agterveld, M., van Soolingen, D., Kuijper, S., Bunschoten, A., Molhuizen, H., Shaw, R. \& other authors (1997). Simultaneous detection and strain differentiation of Mycobacterium tuberculosis for diagnosis and epidemiology. J Clin Microbiol 35, 907-914.

Kent, P. T. \& Kubica, G. P. (1985). Public Health Mycobacteriology. A Guide for the Level III Laboratory. Atlanta, GA: Centers for Disease Control, US Department of Health and Human Services.

Kubica, G. P. (1973). Differential identification of mycobacteria. II. Key features for identification of clinically significant mycobacteria. Am Rev Respir Dis 107, 9-21.
Lopez, B., Aguilar, D., Orozco, H., Burger, M., Espitia, C., Ritacco, V., Barrera, L., Kremer, K., Hernandez-Pando, R. \& other authors (2003). A marked difference in pathogenesis and immune response induced by different Mycobacterium tuberculosis genotypes. Clin Exp Immunol 133, 30-37.

Mardassi, H., Namouchi, A., Haltiti, R., Zarrouk, M., Mhenni, B., Karboul, A., Khabouchi, N., Gey van Pittius, N. C., Streicher, E. M. \& other authors (2005). Tuberculosis due to resistant Haarlem strain, Tunisia. Emerg Infect Dis 11, 957-961.

Niobe-Eyangoh, S. N., Kuaban, C., Sorlin, P., Cunin, P., Thonnon, J., Sola, C., Rastogi, N., Vincent, V. \& Gutierrez, M. C. (2003). Genetic biodiversity of Mycobacterium tuberculosis complex strains from patients with pulmonary tuberculosis in Cameroon. J Clin Microbiol 41, 2547-2553.

Riou, S., el Younsi, C. \& Chaabouni, H. (1989). Consanguinity in the population of northern Tunisia. Tunis Med 67, 167-172.

Scott, A. N., Menzies, D., Tannenbaum, T. N., Thibert, L., Kozak, R., Joseph, L., Schwartzman, K. \& Behr, M. A. (2005). Sensitivities and specificities of spoligotyping and mycobacterial interspersed repetitive unit-variable-number tandem repeat typing methods for studying molecular epidemiology of tuberculosis. J Clin Microbiol 43, 89-94.

Sola, C., Filliol, I., Gutiérrez, C., Mokrousov, I., Vincent, V. \& Rastogi, N. (2001). Spoligotype database of Mycobacterium tuberculosis: biogeographical distribution of shared types and epidemiological and phylogenetic perspectives. Emerg Infect Dis 7, 390-396.

Supply, P., Mazars, E., Lesjean, S., Vincent, V., Gicquel, B. \& Locht, C. (2000). Variable human minisatellite-like regions in the Mycobacterium tuberculosis genome. Mol Microbiol 36, 762-771.

Tunisian Ministry of Health (1999). National Programme of Tuberculosis: Technical Guide, 2nd edn.

Tunisian Ministry of Health (2005). Tuberculosis in Tunisia: Annual Report.

Van Soolingen, D., De Haas, P. E. W., Hermans, P. W. M., Groenen, P. M. A. \& van Embden, J. D. A. (1993). Comparison of various repetitive DNA elements as genetic markers for strain differentiation and epidemiology of Mycobacterium tuberculosis. J Clin Microbiol 31, 1987-1995.

Vitol, I., Driscoll, J., Kreiswirth, B., Kurepina, N. \& Bennett, K. P. (2006). Identifying Mycobacterium tuberculosis complex strain families using spoligotypes. Infect Genet Evol 6, 491-504.

Zozio, T., Allix, C., Gunal, S., Saribas, Z., Alp, A., Durmaz, R., FauvilleDufaux, M., Rastogi, N. \& Sola, C. (2005). Genotyping of Mycobacterium tuberculosis clinical isolates in two cities of Turkey: description of a new family of genotypes that is phylogeographically specific for Asia Minor. BMC Microbiol 5, 44. 